\title{
Simulation on Operational Characteristics of a Valveless Self-excited Pulse Combustor of the Helmholtz-type
}

\author{
$\mathrm{Xu}$ Yao \\ School of Energy Science and Engineering \\ Harbin Institute of Technology \\ Harbin, China \\ xuyao_sure@126.com \\ Zhai Ming* \\ School of Energy Science and Engineering \\ Harbin Institute of Technology \\ Harbin, China \\ zhaiming@hit.edu.cn \\ Ge Tiezhu \\ School of Energy Science and Engineering
}

\author{
Harbin Institute of Technology \\ Harbin, China \\ 370873506@qq.com \\ Dong Peng \\ School of Energy Science and Engineering \\ Harbin Institute of Technology \\ Harbin, China \\ dongp@ hit.edu.cn \\ Huang Yudong \\ School of Chemical Engineering and Technology \\ Harbin Institute of Technology \\ Harbin, China \\ huangyd@hit.edu.cn
}

* Corresponding author

\begin{abstract}
Pulse combustion as an advanced combustion has many advantages, such as high combustion efficiency, low pollution emissions. Due to the complex mechanism of pulse combustion, narrow adjustment range of load, it is difficult to achieve a large-scale application. For this reason, the pulse combustion process is investigated by means of simulation in this paper, and the effects of some parameters on the combustion process are analyzed including the inlet pressure, excess air ratio, decoupling chamber pressure and wall temperature of the combustion chamber. The results indicate that the stable pulse combustion could be produced in the combustor when the temperature of the combustion chamber is from $800 \mathrm{k}$ to $1400 \mathrm{k}$. With the excess air coefficient increased, the pulsation frequency gradually decreases. As the excess air coefficient or inlet pressure increases, the pressure in the combustor gradually increases. The combustor performance could be controlled by adjusting the decoupling chamber pressure.
\end{abstract}

Keywords- numerical simulation;pulse combustion; stability; operational characteristics;adjusting methods

\section{INTRODUCTION}

Pulse combustion is a periodic combustion process under certain acoustic conditions. The temperature, pressure and flow velocity inside the combustor varies periodically. Pulse combustion technology has attracted more and more attention due to its being low pollution emission, high efficient combustion and heat transfer coefficient. Kazuo [1, 2] et al. developed a double valveless pulse combustor to achieve a valveless pulse combustor. Datt [3, 4] et al. (2009) investigated the nonlinear characteristics of the pulse combustor. The stable pulse combustion can be formed when the wall temperature reaches $1140 \mathrm{~K}$; pulsation began to decay when the wall temperature rises to $1160 \mathrm{k}$, forming steady combustion eventually; flameout occurs when the wall temperature is below $1025 \mathrm{k}$. Bloom $[5,6]$ et al. (2009) established lumped parameter model considering the impact of friction, analyzed the pressure and velocity by means of asymptotic expansion method, and concluded that the presence of friction in tailpipe had a significant influence on pulsation of pressure and velocity. Kilicarslan [7, 8] et al. (2007) analyzed gas-fired pulse combustion. The result indicated that the acoustic pressure could be reduced, and the difference between the inlet pressure and outlet pressure could be increased by increasing the length of the tail pipe at the same frequency.

Until now, there are few theoretical studies on pulse combustion. Understanding the mechanism of pulse combustion is necessary for the pulse combustor design and optimization $[9,10]$. Hence, in this study, the pulse combustion mechanism is investigated by simulation and several typical factors are also investigated.

\section{MATHEMATICAL MODEL}

The large eddy simulation (LES) is introduced for modeling turbulence in this work. The governing equations are described as follows:

$$
\begin{gathered}
\frac{\partial \rho}{\partial t}+\frac{\partial}{\partial x_{i}}\left(\rho \overline{u_{i}}\right)=0 \\
\frac{\partial}{\partial t}\left(\rho \bar{u}_{i}\right)+\frac{\partial}{\partial x_{j}}\left(\rho \overline{u_{i}} \bar{u}_{j}\right)=\frac{\partial}{\partial x_{j}}\left(\mu \frac{\partial \sigma_{i j}}{\partial x_{j}}\right)-\frac{\partial \bar{p}}{\partial x_{i}}-\frac{\partial \tau_{i j}}{\partial x_{j}}(2)
\end{gathered}
$$


where $\sigma \mathrm{ij}$ is the stress tensor due to molecular viscosity defined by:

$$
\sigma_{i j}=\left[\mu\left(\frac{\partial \bar{u}_{i}}{\partial x_{j}}+\frac{\partial \bar{u}_{j}}{\partial x_{i}}\right)\right]-\frac{2}{3} \mu \frac{\partial \bar{u}_{l}}{\partial x_{l}} \delta_{i j}
$$

For the pulse combustion process, the species transport equations take the following form:

$$
\frac{\partial}{\partial t}\left(\rho Y_{i}\right)+\nabla \cdot\left(\rho \vec{v} Y_{i}\right)=-\nabla \cdot \overrightarrow{J_{i}}+R_{i}+S_{i}
$$

Where $\vec{J}_{i}$ is the diffusion flux of species $i$, which arises due to concentration gradients:

$$
\vec{J}_{i}=-\left(\rho D_{i, m}+\frac{\mu_{t}}{S c_{t}}\right) \nabla Y_{\mathrm{i}}
$$

\section{RESULTS AND DISCUSSION}

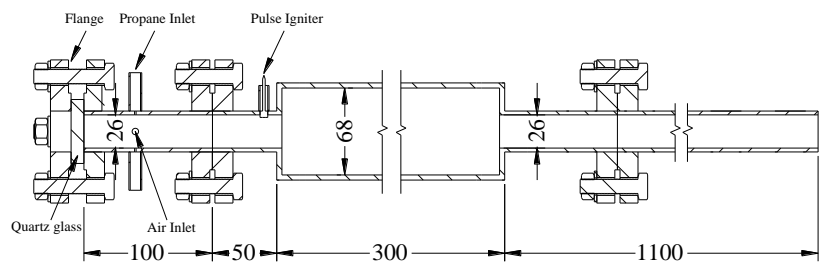

Figure 1.

Schematic diagram of pulse combustor system

In this work, the valveless self-excited pulse combustor of the Helmholtz-type is selected as the research objective. The combustible gas is propane. Fig.1 shows the schematic diagram of combustor, which consists of mixing chamber, combustion chamber and tailpipe. Mixing chamber has a $100 \mathrm{~mm}$ length and $26 \mathrm{~mm}$ pipe diameter. The length and diameter of the combustion chamber are $300 \mathrm{~mm}$ and $68 \mathrm{~mm}$ respectively. The tailpipe has an $1100 \mathrm{~mm}$ length and $26 \mathrm{~mm}$ pipe diameter. The diameter of propane and air inlet is $5 \mathrm{~mm}$ and $1 \mathrm{~mm}$, respectively. In order to avoid the noise during operation and stabilize the tail pipe pressure, a decoupling chamber is set up at the end of the tailpipe, which has $800 \mathrm{~mm}$ length and $500 \mathrm{~mm}$ diameter.
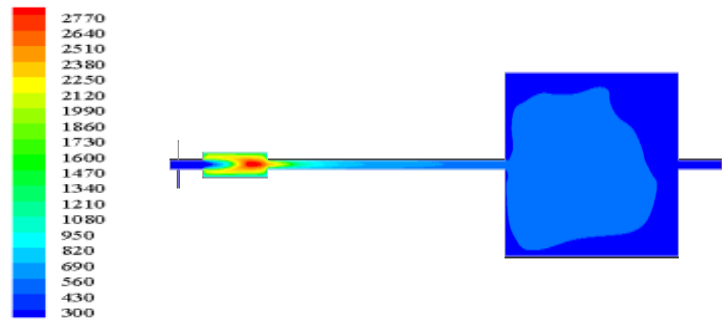

Figure 2. Contour of temperature in the pulse combustor.

Fig. 2 shows the contours of temperature in the system. It can be found that there is a high temperature in the middle and rear of the combustion chamber. The temperature is relatively lower near the inlet and outlet. It implies that the propane mixed with the air in the mixing chamber adequately, the whole pulse combustion process has been substantially completed in the combustion chamber, which is consistent with the experiment phenomenon.

\section{A. Effect of inlet pressure on the averaged pressure amplitude}

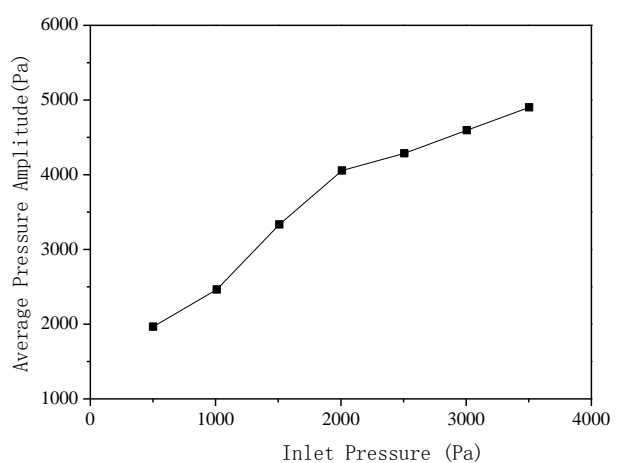

Figure 3. Effect of inlet pressure on the averaged pressure amplitude

The effect of inlet pressure on averaged pressure amplitude is evaluated as shown in Fig. 3. It can be found that with the inlet pressure increased, averaged pressure amplitude in the combustion chamber shows a rising trend. An increase in inlet pressure hinders the gas reverse flow after combustion, which reduces heat loss and improves combustion intensity. Hence, when the inlet pressure in below $2000 \mathrm{~Pa}$, the trend of the curve is obvious. As the pressure continues to increase, the degree of the growth becomes weak.

\section{B. Effect of inlet pressure on the frequency}

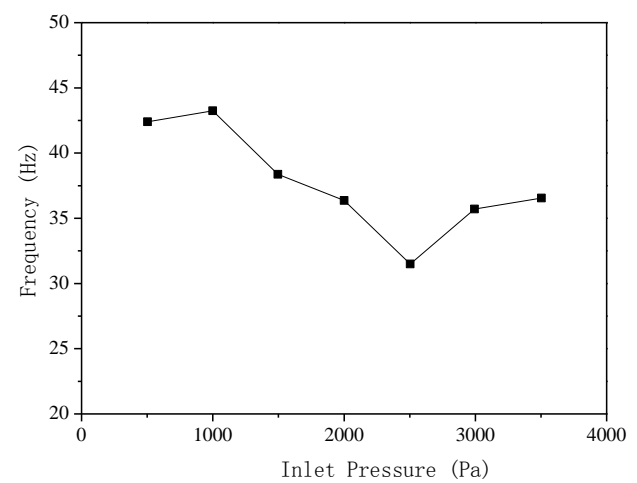

Figure 4.

Effect of inlet pressure on the frequency

Fig.4 shows the variation of frequency with inlet pressure. It can be found that when the inlet pressure is 
below $2500 \mathrm{~K}$, the frequency decreases with the increasing inlet pressure. Above $2500 \mathrm{~K}$, the frequency has a slight increase. However, from the magnitude of the frequency, it can be observed that the difference is not obvious. It implies that the effect of inlet pressure on the frequency is not significant.

\section{Effect of wall temperature of the combustion chamber on operation stability}

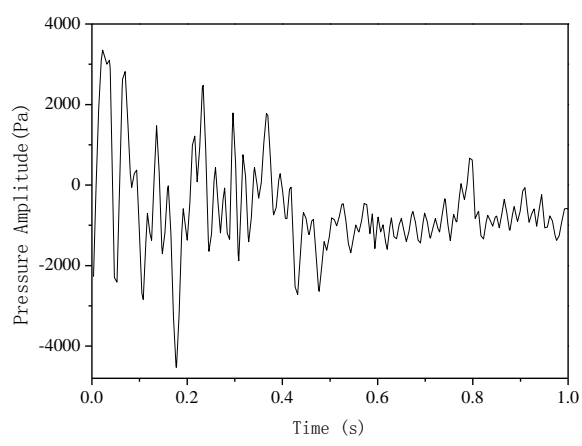

Figure 5. Effect of wall temperature of the combustion chamber on operation stability

To investigate the effect of wall temperature, the wall temperature in the combustion chamber varies from $800 \mathrm{~K}$ to $1600 \mathrm{~K}$. When the wall temperature is below $1400 \mathrm{~K}$, the stable pulse combustion can be achieved. Fig. 6 shows the variation of pressure amplitude with time at the wall temperature of $1600 \mathrm{~K}$. In the beginning, the fluctuation of pressure amplitude is obvious. Then the fluctuation becomes weak. It implies that when wall temperature reaches $1600 \mathrm{~K}$, the stable pulse combustion can be formed The reason for this is that a high wall temperature enhances the fuel temperature and promotes the reaction rate. When the fuel amount cannot meet the required amount for combustion, the fluctuation pressure gradually disappears.

\section{Effect of the excess air coefficient on pressure amplitude of the combustion chamber}

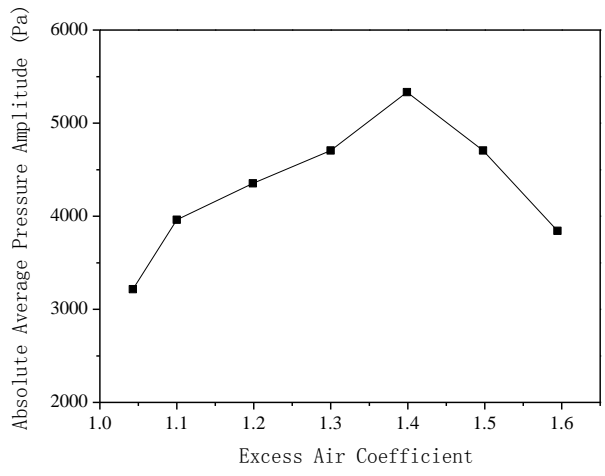

Figure 6. Effect of the excess air coefficient on pressure amplitude of the combustion chamber

Fig.6 displays the impact of the excess air ratio on the absolute averaged pressure amplitude. It can be found that the pressure amplitude first increases and then decreases with excess air ratio improved. At the excess air ratio of 1.4 , the maximum value is reached. It is attributed to that at a low excess air ratio, increasing the excess air ratio means an increase in the inlet pressure, which enhances pressure in the chamber. When excess air ratio reaches a certain level, the fraction of fuel in the mixture gas becomes low, which results in an adequate combustion and reduces absolute averaged pressure amplitude.

\section{E. Effect of decoupling chamber pressure on the pressure of the combustion chamber}

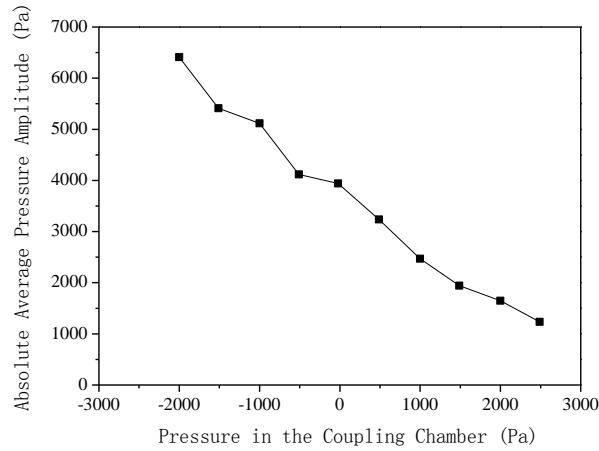

Figure 7. Effect of decoupling chamber pressure on the pressure of the combustion chamber

The variation of absolute averaged pressure amplitude with decoupling chamber pressure is shown in Fig. 7. When decoupling chamber pressure is below the environmental pressure, pressure amplitude in the combustion chamber decreases with increasing decoupling chamber pressure. It is because increasing decoupling chamber pressure makes an increase of gas temperature and promotes the reaction rate, which leads to the heat accumulation and reduction of the phase difference 
between released heat and pressure pulsation. Hence, the pressure is improved. However, a high decoupling chamber pressure decreases the difference between the inlet and outlet pressure, and hinders the pressure.

\section{CONCLUSION}

In this work, the pulse combustion process is investigated by simulation. Some factors affecting the performance are analyzed. The results indicate that the pulsation frequency decreases with excess air ratio increased. The pressure is proportional to excess air ratio and inlet pressure.

From the investigation of the effect of wall temperature on the operation stability, the stable pulse combustion can be achieved when the wall temperature in the combustion chamber lies in the range between $800 \mathrm{k}$ and 1400k.

\section{ACKNOWLEDGMENT}

This work was supported by National Natural Science Foundation for Young Scholars of China (Grant N o.51206032), China Postdoctoral Science Foundation (Gra nt No.2013M531037), Heilongjiang Postdoctoral Financial Assistance (Grant No.LBH-Z12101).

\section{REFERENCES}

[1] K. Saito, K. Eguchi, M. Gomi, T. Saito. Fundamental Operating Mechanism for a Twin Valveless Pulse Combustor .1993, 94(16):11 24
[2] I. Hongo, K.Saito. Development of Small Twin-Valveless Pulse Combustors-Effect of Injection System. Combustion Science and Technology . 1993, 94(1-6): 43 55

[3] S. Datta, S. Mondal, A. Mukhopadhyay, D. Sanyal, S. Sen. An Investigation of Nonlinear Dynamics of a ThermalPulse Combustor. Combustion Theory and Modelling. 2009, 13(1):17 38

[4] A.Mukhopadhyay, S. Datta, D. Sanyal. Effects of Tailpipe Friction On the Nonlinear Dynamics of a Thermal Pulse Combustor. Journal of Engineering for Gas Turbines and Power. 2008, 130(1):11507 11509

[5] F. Bloom, T. Patterson. The Effect of Tailpipe Friction On Pressure and Velocity Oscillations in a Nonlinear, Lumped Parameter, Pulse Combustor Model. Nonlinear Analysis-Real World Applications. 2009, 10(5):3002 3017

[6] F. Bloom, F. Ahrens, T . Patterson . The Nonlinear Dynamical System Generated by the Akt Pulse Combustor Model. Nonlinear Analysis-Theory Methods \& Applications. 2005, 63(5-7):891 901

[7] A. Kilicarslan, A. Arisoy. Acoustic Analysis of a Liquefied Petroleum Gas-Fired Pulse Combustor. Applied Acoustics. 2008, 69(9):770 777

[8] A. Kilicarslan. Frequency Evaluation of a Gas-Fired Pulse Combustor. International Journal of Energy Research. 2005, 29(5):439 454

[9] T. Kudra. Pulse-Combustion Drying: Status and Potentials. Drying Technology. 2008, 26(12):1409 1420

[10] A. W. Mazlan, U. M. Haffis, M. S. Mohsin. Impulse Measurement of Pulse Combustion Tube Using Accelerometer. Proceedings of the Ninth Asia-Pacific International Symposium on Combustion and Energy Utilization. 2008: 211 216 